\title{
Pengaruh Sistem Informasi Kepegawaian Terhadap Efektivitas Kerja Karyawan Rumah Sakit Muhammadiyah Bandung
}

\section{The Effect of Personnel Information Systems on the Work Effectiveness of Muhammadiyah Hospital Employees in Bandung}

\author{
Lusi Liani Lestari ${ }^{1}$, Ai Susi Susanti ${ }^{2}$ \\ ${ }^{12}$ Politeknik Piksi Ganesha \\ lusiliani2@gmail.com,aisusi@piksi.ac.id \\ Jalan Jend Gatot Subroto 301 Kota Bandung
}

\begin{abstract}
ABSTRAK
Penelitian ini bertujuan untuk mengetahui pengaruh penerapan sistem informasi dengan mengkhususkan pada sistem informasi kepegawaian terhadap efektivitas kerja karyawan bidang sumber daya manusia di Rumah Sakit Muhammadiyah Bandung. Bertambah luasnya wilayah kerja dan tingginya tingkat kunjungan pasien maka jumlah pegawai semakin meningkat. Pencatatatan data kepegawaian yang masih dilakukan secara manual dan tidak tercatat baik dalam sebuah sistem akan kesulitan dalam pencarian dan pembuatan rekapitulasi data pegawai, hal tersebut kurang efektif dan efisien yang menyebabkan beban waktu kerja bertambah, untuk itu diperlukan suatu sistem informasi yang dapat menangani permasalahan tersebut. Jenis penelitian ini menggunakan metode pengambilan sampel non probability sampling dengan jenis sampel jenuh untuk pengumpulan data. Penelitian ini menggunakan metode deskriptif kuantitatif dan metode analisis data menggunakan teknis analisis uji regresi linear sederhana dan Koefisien Determinasi. Hasil penelitian dari 20 responden menunjukan bahwa berdasarkan dari hasil uji regresi linear sederhana koefisien regresi pada variabel X memperoleh sebesar 0,769. Koefisien regresi tersebut bernilai positif, sehingga dapat dikatakan bahwa arah pengaruh variabel X terhadap variabel $\mathrm{Y}$ adalah positif. Dan berdasarkan hasil koefisien determinasi $\left(\mathrm{R}^{2}\right)$ memperoleh $\mathrm{R}$ square sebesar 0,723 yang menunjukan bahwa variabel $\mathrm{X}$ memiliki pengaruh sebesar 72,3\% terhadap variabel Y. Secara keseluruhan penelitian ini dapat disimpulkan bahwa variabel bebas mempunyai pengaruh yang signifikan terhadap variabel efektivitas kerja. Penerapan sistem informasi kepegawaian diharapkan mampu mengatasi berbagai kendala yang dihadapi para pekerja di bidang sumber daya manusia dalam mengolah data kepegawaian.
\end{abstract}

Kata Kunci : Sistem Informasi, Efektivitas Kerja, Sumber Daya Manusia

\section{ABSTRACT}

This study aims to determine the effect of implementing information systems by specializing in personnel information systems on the work effectiveness of employees in the field of human resources at Muhammadiyah Hospital Bandung. As the area of work increases and the level of patient visits increases, the number of employees increases. Staffing data recording that is still done manually and not recorded properly in a system will have difficulty in finding and making employee data recapitulation, it is less effective and efficient which causes the work time load to increase, for that we need an information system that can handle these problems. This type of research uses a nonprobability sampling method with a saturated sample type for data collection. This study uses quantitative descriptive methods and data analysis methods using simple linear regression analysis techniques and the Coefficient of Determination. The results of the research from 20 respondents showed that based on the results of a simple linear regression test the regression coefficient on the $X$ variable was 0.769. The regression coefficient is positive, so it can be said that the direction of the influence of variable X on variable $Y$ is positive. And based on the results of the coefficient of determination (R2) obtained an $R$ square of 0.723 which indicates that the $X$ variable has an influence of $72.3 \%$ on the $Y$ variable. Overall, this study can be concluded that the independent variables have a significant influence on the work effectiveness variable. The application of the personnel information system is expected to be able to overcome various obstacles faced by workers in the field of human resources in processing personnel data.

Keywords: Information Systems, Work Effectiveness, Human Resources 
Lusi Liani Lestari, Ai Susi Susanti : Pengaruh Sistem Informasi Kepegawaian Terhadap ....

\section{PENDAHULUAN}

Perkembangan teknologi masa kini sudah berkembang pesat dan terus berevolusi. Berikut hal nya dengan sebuah sistem informasi yang kini menjadi komponen penting bagi suatu perusahaan atau instansi dalam menyelesaikan suatu pekerjaan agar lebih efektif dan efisien. Sistem informasi merupakan sistem yang menghasilkan informasi untuk kepentingan manajerial atau proses dalam manajemen yaitu perencanaan, pelaksanaan, pemantauan dan penilaian kegiatan organisasi (Hidayat, 2019). Dalam hal ini, sistem informasi tidak hanya bertujuan untuk menghasilkan pelaporan atau informasi saja, namun juga mengelola agar operasional sebuah organisasi atau manajemen menjadi lebih efektif dan efisien. Ilmu sistem informasi akan dapat dijalankan asalkan sumber daya manusia dalam sebuah organisasi tersebut memang dapat diandalkan. Sumber Daya Manusia merupakan salah satu aset penting dalam sebuah Perusahaan atau Instansi untuk mencapai tujuan, tanpa Sumber Daya Manusia yang baik, perusahaan tidak dapat berjalan dengan lancar untuk mencapai tujuannya (Beti, 2019).

Sistem Informasi Manajemen Rumah sakit merupakan suatu sistem yang digunakan untuk mengumpulkan data-data manajemen dari suatu rumah sakit, yang didalam nya banyak instalasi, departemen maupun unit-unit yang tergabung dalam suatu sistem yang lengkap (Hayatunnisa et al., 2020). Terselenggaranya Sistem Informasi Manajemen (SIM) bagi suatu rumah sakit merupakan hal yang sangat penting dalam penerapannya di era masa kini. Hal ini didukung dengan semakin kompleksnya permasalahan yang ada dalam data medis pasien maupun data-data administrasi lain yang terkait dengan penyelenggaraan pelayanan rumah sakit yang diterima pasien tersebut (Sudiarti et al., 2019). Rumah sakit diharapkan mampu menghasilkan pelayanan yang berkualitas dengan harga yang kompetitif. Hal tersebut dapat terwujud apabila rumah sakit memiliki Sumber Daya Manusia yang kompeten dibidangnya. Untuk itu diperlukan manajemen SDM yang efektif agar tujuan organisasi dapat tercapai dengan baik (Mailani \& Muhadi, 2016). Efektivitas merupakan gambaran tingkat keberhasilan atau keunggulan dalam mencapai sasaran yang telah ditetapkan dan adanya keterkaitan antara nilai-nilai bervariasi (Waruwu, 2018). Rumah Sakit Muhammadiyah Bandung merupakan suatu instansi yang menyelanggarakan pelayanan kesehatan di bawah pemerintahan daerah kota Bandung, dengan bertambah luasnya wilayah kerja dan tingginya tingkat kunjungan pasien, Rumah Sakit Muhammadiyah Bandung memiliki jumlah pegawai yang semakin meningkat. Sumber daya manusia memiliki begitu banyak data yang mencakup ketenagakerjaan yang ada dalam lingkungan perusahaan. Oleh karena itu, hal ini dapat 
menjadi suatu masukan terhadap Sistem Informasi Sumber Daya Manusia. Sistem Informasi Sumber Daya Manusia diharapkan dapat melakukan pengolahan terhadap data yang ada menjadi suatu informasi yang dapat di analisa dan mendukung pengambilan suatu keputusan. Dengan adanya penerapan sistem informasi kepegawaian, pegawai yang bekerja di bidang Sumber Daya Manusia akan terbantu dalam menyelesaikan suatu pekerjaan yang diantaranya melakukan pencatatan data kandidat pegawai, memilih kandidat yang sesuai dengan kriteria yang diinginkan, baik dari pihak departemen personalia atau departemen dimana calon karyawan baru tersebut akan bekerja. Selain itu juga Sistem Informasi Kepegawaian dapat digunakan untuk mencatat informasi cuti karyawan, masa berlakunya kontrak karyawan, dan masa pensiun karyawan. Sama hal nya dalam artikel (Setiyadi \& Hakam, 2015) mengemukakan bahwa petugas juga menyadari, bahwa perlu dibuat sistem yang membantu mereka dalam melakukan pencatatan dan pengolahan data, sehingga nantinya akan mempermudah mereka dalam menjalankan tugas dan membuat laporan kepada pimpinan.

Di dalam Keputusan (Menteri Dalam Negeri No.17, 2000) disebutkan bahwa: "Sistem Informasi Manajemen Kepegawaian merupakan suatu totalitas terpadu yang terdiri dari perangkat pengolah meliputi pengumpul prosedur, tenaga pengolah dan perangkat lunak, perangkat penyimpanan meliputi pusat data dan bank data serta perangkat komunikasi yang saling berkaitan, saling ketergantungan dan saling menentukan dalam rangka penyediaan informasi di bidang kepegawaian”. Menurut Priyanto SIMPEG (Sistem Informasi Manajemen Pegawai) didefinisikan sebagai Sistem Informasi terpadu, yang meliputi pendataan pegawai, pengolahan data, prosedur, tata kerja, sumber daya manusia dan teknologi informasi untuk menghasilkan informasi yang cepat, lengkap dan akurat dalam rangka mendukung administrasi kepegawaian (Suryana, 2018). Menurut DeLone dan Mclean dalam artikel (Rohani \& Hati, 2018) mengemukakan bahwa sistem informasi dapat diukur dengan beberapa faktor yaitu Kualitas sistem, Kualitas informasi, Pengguna, Kepuasaan pengguna.

Berdasarkan paparan di atas, tujuan penelitian ini adalah untuk mengetahui seberapa besarnya Pengaruh Sistem Informasi Kepegawaian terhadap Efektivitas Kerja pada Karyawan Bidang Sumber Daya Manusia di RS Muhammadiyah Bandung.

\section{METODE}

Penelitian ini menggunakan penelitian kuantitatif dengan pendekatan deskriptif. Penelitian tersebut dilaksanakan di Rumah Sakit Muhammadiyah Bandung pada Bulan 
Juni 2021. Populasi dalam penelitian ini adalah seluruh pegawai bidang sumber daya manusia di Rumah Sakit Muhammadiyah Bandung. Sampel penelitian adalah sebagian dari populasi yang diambil sebagai sumber data dan dapat mewakili seluruh populasi. Penentuan jumlah sampel pada penelitian ini menggunakan jenis Non Probability Sampling dengan teknik sampling jenuh sejumlah 20 orang. Sampling jenuh sendiri merupakan teknik penentuan sampel yang menjadikan seluruh anggota populasi sebagai sampel penelitian (Erliana et al., 2019). Hal tersebut sering dilakukan apabila jumlah populasi kecil, kurang dari 30 orang. Teknik pengumpulan data merupakan proses yang penting dalam mendukung suatu penelitian. Menurut Sugiyono dalam (Ismail \& Sudarmadi, 2019) teknik pengumpulan data merupakan langkah yang paling strategis dalam penelitian, karena tujuan utama dari penelitian adalah mendapatkan data tanpa mengetahui teknik pengumpulan data, maka penelitian tidak akan mendapatkan data yang memenuhi standar data yang ditetapkan. Dalam penelitian ini peneliti menggunakan dua macam data menurut klasifikasi jenis dan sumbernya, yaitu data primer. Teknik pengumpulan data primer tersebut dilakukan dengan instrument Metode Angket/ Kuesioner digunakan sebagai alat pendamping dalam mengumpulkan data. Daftar dibuat pertanyaan semi terbuka yang memberi pilihan jawaban pada responden dan memberikan penjelasan-penjelasan yang diperlukan oleh penullis, lalu yang kedua data sekunder. Teknik pengumpulan data sekunder dilakukan dengan instrument penelitian kepustakaan yaitu dengan mengumpulkan data dan informasi melalui literature yang relevan dengan judul penelitian seperti buku-buku, artikel dan makalah yang memiliki relevansi dengan masalah yang diteliti. Penyajian data diteliti dan dianalisis dengan program SPSS for Windows. Metode analisis data menggunakan teknis analisis uji regresi linear sederhana dan Koefisien Determinasi.

Analisis regresi linier sederhana adalah hubungan secara linear antara satu variabel independen $(\mathrm{X})$ dengan variabel dependen $(\mathrm{Y})$. Analisis regresi sederhana dapat digunakan untuk mengetahui arah dari hubungan antara variabel bebas dengan variabel terikat, apakah memiliki hubungan positif atau negatif serta untuk memprediksi nilai dari variabel terikat apabila nilai variabel bebas mengalami kenaikan ataupun penurunan (Mulyono, 2019). Dengan Persamaan Umum regresi linier sederhana $Y=a+b X$. Koefisien Determinasi ini digunakan untuk mengukur seberapa besar pengaruh Sistem Informasi Kepegawaian terhadap Efektivitas Kerja. Nilai koefisien determinasi adalah nol dan satu. Nilai $\mathrm{R}^{2}$ yang kecil berarti kemampuan variabel-variabel independen dalam menjelaskan variasi variabel dependen amat terbatas. Nilai yang mendekati satu berarti 
variabel-variabel independen memberikan hampir semua informasi yang dibutuhkan untuk memprediksi variasi-variabel dependen.

\section{HASIL}

Analisis statistik deskriptif adalah statistik yang digunakan untuk menganalisis data dengan cara mendeskripsikan atau menggambarkan data yang telah terkumpul sebagaimana adanya tanpa bermaksud membuat kesimpulan yang berlaku untuk umum atau generalisasi.Teknik analisis statistik deskriptif yang dapat digunakan antara lain: Penyajian data dalam bentuk tabel atau distribusi frekuensi dan tabulasi silang (crosstab). Dengan analisis ini akan diketahui kecenderungan hasil temuan penelitian, apakah masuk dalam kategori rendah, sedang atau tinggi. Hasil dari pengolahan data dan analisis data menunjukan bahwa variabel Sistem Informasi Kepegawaian terhadap variabel Efektivitas Kerja sudah menunjukan hasil yang baik.

Tabel 1. Distribusi Frekuensi Variabel Sistem Informasi Kepegawaian (X)

\begin{tabular}{|c|c|c|c|c|c|c|c|c|c|c|c|c|c|}
\hline \multirow{2}{*}{ Item } & \multicolumn{2}{|c|}{ STS } & \multicolumn{2}{|r|}{$\mathrm{TS}$} & \multicolumn{2}{|c|}{ KS } & \multicolumn{2}{|r|}{$\mathrm{S}$} & \multicolumn{2}{|c|}{ SS } & \multicolumn{2}{|c|}{ TOTAL } & \multirow{2}{*}{$\begin{array}{l}\text { Rata- } \\
\text { rata }\end{array}$} \\
\hline & $\mathrm{F}$ & $\%$ & $\mathrm{~F}$ & $\%$ & $\mathrm{~F}$ & $\%$ & $\mathrm{~F}$ & $\%$ & $\mathrm{~F}$ & $\%$ & $\mathrm{~F}$ & $\%$ & \\
\hline $\mathrm{X} 1$ & 0 & 0,00 & 0 & 0,00 & 3 & 15,00 & 14 & 70,00 & 3 & 15,00 & 20 & 100,00 & 4,00 \\
\hline $\mathrm{X} 2$ & 0 & 0,00 & 3 & 15,00 & 8 & 40,00 & 7 & 35,00 & 2 & 10,00 & 20 & 100,00 & 3,40 \\
\hline $\mathrm{X} 3$ & 0 & 0,00 & 3 & 15,00 & 7 & 35,00 & 10 & 50,00 & 0 & 0,00 & 20 & 100,00 & 3,35 \\
\hline $\mathrm{X} 4$ & 0 & 0,00 & 2 & 10,00 & 3 & 15,00 & 5 & 25,00 & 10 & 50,00 & 20 & 100,00 & 4,15 \\
\hline X5 & 0 & 0,00 & 1 & 5,00 & 5 & 25,00 & 12 & 60,00 & 2 & 10,00 & 20 & 100,00 & 3,75 \\
\hline X6 & 1 & 5,00 & 2 & 10,00 & 3 & 15,00 & 10 & 50,00 & 4 & 20,00 & 20 & 100,00 & 3,70 \\
\hline X7 & 0 & 0,00 & 2 & 10,00 & 1 & 5,00 & 10 & 50,00 & 7 & 35,00 & 20 & 100,00 & 4,10 \\
\hline X8 & 0 & 0,00 & 0 & 0,00 & 4 & 20,00 & 13 & 65,00 & 3 & 15,00 & 20 & 100,00 & 3,95 \\
\hline Rata & & $\overline{\text { otals }}$ & & & & & & & & & & & 3,80 \\
\hline
\end{tabular}

Berdasarkan dari tabel 2 nilai dari rata-rata total skor variabel Sistem Informasi Kepegawaian diketahui sebesar 3,80 yang berarti bahwa secara keseluruhan variabel Sistem Informasi Kepegawaian masuk dalam kategori Baik. 
Tabel 2. Distribusi Frekuensi Variabel Efektivitas Kerja (Y)

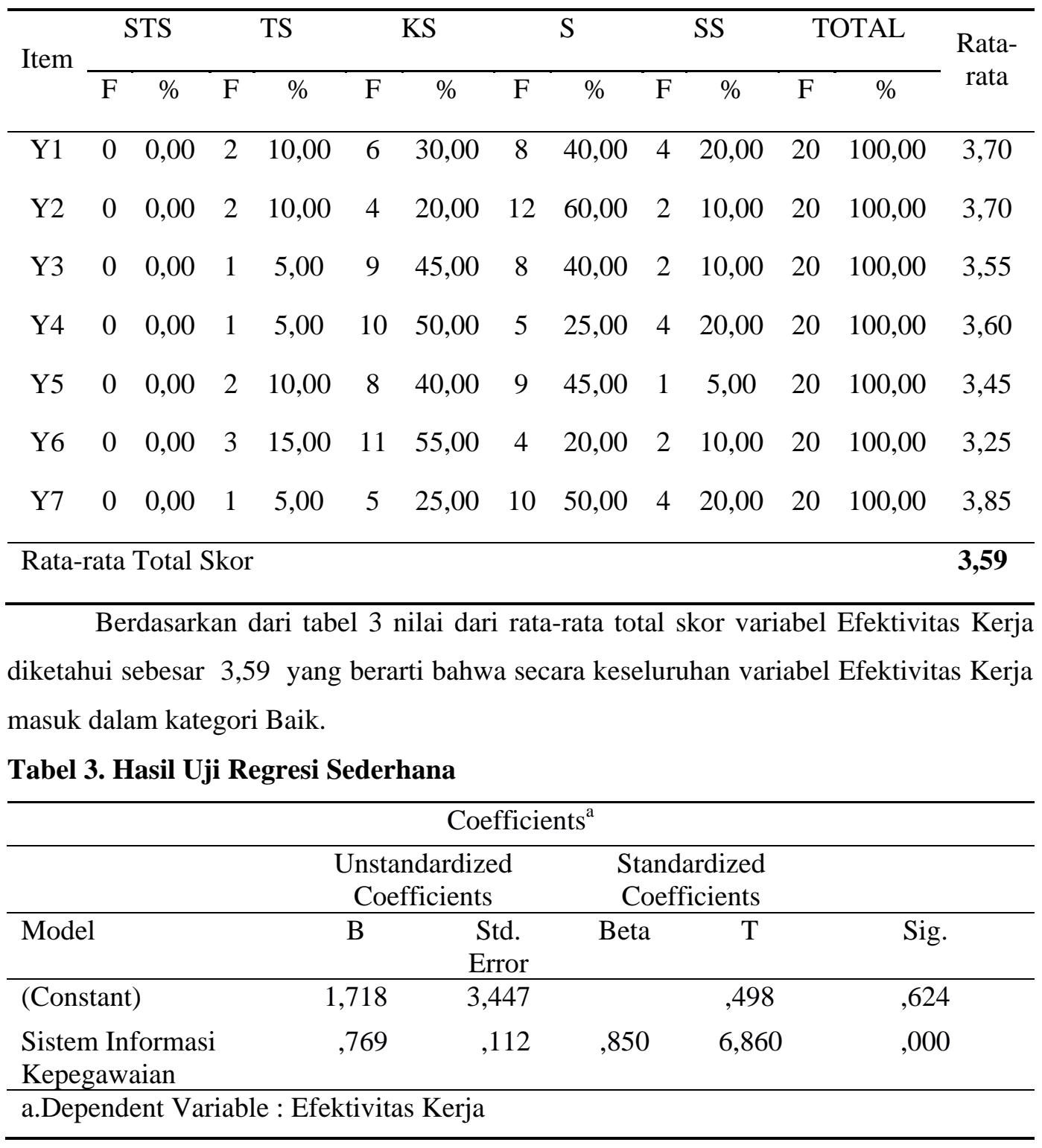

Berdasarkan dari tabel 4. Koefisien regresi $X$ memperoleh sebesar 0,769 menyatakan bahwa setiap penambahan $1 \%$ nilai variabel sistem informasi kepegawaian, maka nilai partisipasi bertambah sebesar 0,769 . Koefisien regresi tersebut bernilai positif, sehingga dapat dikatakan bahwa arah pengaruh variabel $\mathrm{X}$ terhadap variabel $\mathrm{Y}$ adalah positif. Nilai signifikasi dari tabel Coefficients diperoleh nilai signifikasi sebesar $0,000<0,05$ sehingga dapat disimpulkan bahwa variabel Sistem Informasi Kepegawaian (X) berpengaruh terhadap variabel Efektivitas kerja (Y). Untuk dilihat dari hasil nilai $t$ 
diketahui nilai $\mathrm{t}_{\text {hitung }}$ sebesar $6,860>\mathrm{t}_{\text {tabel }} 2,086$ sehingga dapat disimpulkan bahwa variabel $\mathrm{X}$ berpengaruh terhadap variabel $\mathrm{Y}$.

Tabel 4. Hasil Uji Koefisien Determinasi

\begin{tabular}{ccccc}
\hline \multicolumn{5}{c}{ Model Summary } \\
\hline Model & $\mathrm{R}$ & R Square & $\begin{array}{c}\text { Adjusted R } \\
\text { Square }\end{array}$ & $\begin{array}{c}\text { Std. Error of } \\
\text { the Estimate }\end{array}$ \\
\hline 1 &, $850^{\mathrm{a}}$ &, 723 &, 708 & 2,305
\end{tabular}

a. Predictors: (Constant), Sistem Informasi Kepegawaian

Berdasarkan hasil koefisien determinasi $\left(\mathrm{R}^{2}\right)$ menunjukan bahwa $\mathrm{R}$ square sebesar 0,723 yang berarti bahwa sistem informasi kepegawaian memiliki pengaruh dengan memperoleh hasil persentasinya sebesar $72,3 \%$ terhadap efektivitas kerja karyawan bidang SDM di RS Muhammadiyah Bandung.

\section{PEMBAHASAN}

Berdasarkan tabel distribusi jawaban responden diatas, dapat diperoleh informasi bahwa besar pengaruhnya penerapan sistem informasi kepegawaian terhadap karyawan bidang sumber daya manusia di Rumah Sakit Muhammadiyah Bandung memperoleh persentase sebesar $70 \%$. Sedangkan untuk tabel distribusi pada variabel efektivitas kerja memperlihatkan bahwa pernyataan setuju berada pada posisi tinggi dengan jumlah 12 responden dan memperoleh persentase sebesar $60 \%$. Responden yang menjawab setuju dan sangat setuju berpendapat bahwa untuk menjalankan tugas pekerjaan agar lebih mudah maka dibutuhkan sistem informasi kepegawaian. Berdasarkan dari data tabel diatas maka mayoritas responden berpendapat bahwa pegawai memerlukan sistem informasi agar dapat mempermudah pekerjaan. Peran sistem informasi dalam dunia kerja khususnya untuk mengolah data-data secara komputerisasi sangat dibutuhkan sehingga dapat memberikan kemudahan-kemudahan bagi pengguna. Pengolahan data dengan menggunakan komputer akan lebih cepat dan mudah serta dapat disimpan dalam jangka waktu yang lama (Heldiansyah et al., 2016). Perkembangan teknologi di bidang kesehatan akan mampu ber-sinergi dengan baik apabila unsur-unsur pendukung lainnya juga mengimbanginya dengan kemajuan dibidangnya misalnya perkembangan Teknologi Informasi saat ini memampukan keseluruhan manajemen pengolahan data dapat dioptimalkan efektivitas dan efisiensinya (Suharyanto et al., 2017). Sistem informasi manajemen dalam kegiatan manajemen yang baik harus mampu memberikan dukungan pada proses perencanaan, pengendalian, pengambil keputusan. Data yang telah 
diklasifikasi atau diolah atau diinterprestasi untuk digunakan dalam proses pengambilan keputusan adalah informasi. Sistem pengolahan mengolah data menjadi informasi atau tepatnya mengolah data dari bentuk tak berguna menjadi berguna bagi penerimanya (Lipursari, 2013).

Dukungan sistem informasi dalam proses perencanaan adalah rencana yang merupakan suatu arah tindakan yang ditetapkan lebih dulu dan merupakan penggabungan tujuan yang hendak dicapai dan kegiatan yang perlu dilaksanakan untuk mencapai tujuan. Suatu organisasi pada setiap tingkatan mempunyai rencana yang berbeda. Sistem informasi yang dikembangkan harus mampu mendukung setiap kebutuhan tersebut. Selain itu, proses perencanaan yang akan memerlukan suatu model perencanaan, data, masukan, dan manipulasi model untuk menghasilkan keluaran berupa suatu rencana. Sesuai dengan tujuannya, sistem informasi dalam manajemen diharapkan mampu membantu setiap orang yang membutuhkan pengambilan keputusan dengan lebih tepat dan akurat. Tapi, disadari bahwa dengan berbagai peran yang dimiliki dalam aktivitas yang dilaksanakannya, setiap orang berusaha untuk dapat memenuhi tugas dan tanggung jawab yang dibebankan kepadanya dengan baik. Dalam usaha memecahkan suatu masalah, pemecah masalah mungkin membuat banyak keputusan. Keputusan merupakan rangkaian tindakan yang perlu diikuti dalam memecahkan masalah untuk menghindari dan mengurangi dampak negatif atau untuk memanfaatkan kesempatan. Kondisi ini menjadi tidak mudah dengan semakin rumitnya aktivitas dan keterbatasan sumber daya yang tersedia. Apalagi informasi yang dibutuhkan tidak berasal langsung dari sumbernya. Untuk itu manajemen sebagai pengguna informasi membutuhkan suatu sistem pendukung (support systems) yang mampu meningkatkan pengambilan keputusannya, sistem informasi dalam manajemen terutama untuk kondisi yang tidak terstruktur ataupun sistem pendukung untuk tingkatan tertentu saja.

Menurut (Djahir \& Pratita, 2014) Ada dua alasan penting mengapa manajemen membutuhkan suatu sistem pendukung yang mampu untuk meningkatkan pengambilan keputusan dalam suatu perusahaan atau instansi, yaitu keputusan untuk membangun sistem informasi yang dapat memenuhi kebutuhan manajemen tingkat atas, yaitu dengan hanya mengandalkan sistem informasi manajemen tanpa bantuan sistem pendukungnya, sulit bagi manajemen terutama di tingkat atas untuk mengambil keputusan yang strategis. Kebutuhan untuk menciptakan pelaporan dan proses pengambilan keputusan yang memiliki arti (makna), yaitu manajemen disini didorong untuk bagaimana mengembangkan pelaporan yang lebih baik lagi untuk pengukuran kinerja aktivitas yang 
dilaksanakannya dan menginformasikan berbagai tipe pengambilan keputusan yang baru. Dengan bantuan sistem pendukung yang disiapkan, maka hal ini akan lebih memungkinkan manajemen untuk mendapatkan pelaporan dan proses pengambilan keputusan yang lebih baik lagi.

Kemampuan sebuah sistem informasi dalam perusahaan, yaitu pengetahuan tentang bagaimana potensi kemampuan sistem informasi yang dikomputerisasi akan dapat memungkinkan seorang manajer secara sistematis menganalisis masing-masing tugas organisasi dan menyesuaikannya dengan kemampuan komputer. Dengan kata lain, sistem informasi adalah sebagai suatu sistem berbasis komputer yang menyediakan informasi bagi beberapa pemakai dengan kebutuhan yang sama. Dengan adanya sistem informasi manajemen dalam suatu perusahaan diharapkan suatu sistem dapat bekerja secara cepat dan akurat, sehingga produktivitas kerja di sebuah perusahaan atau instansi akan lebih meningkat. Sumber daya manusia (SDM) merupakan faktor yang paling penting karena manusialah yang akan melaksanakan semua proses organisasi dan manusia yang akan melaksanakan fungsi-fungsi dan aktifitas organisasi yang bersangkutan (Arisuniarti, 2016).

Karyawan atau sumber daya manusia yang bekerja dalam sebuah perusahaan atau instansi umumnya diterima melalui proses seleksi terlebih dulu. Dalam proses tersebut, data-data para pegawai dikumpulkan sebagai catatan internal yang terdiri dari nama karyawan, tempat dan tanggal lahir, alamat rumah, status pernikahan,pengalaman kerja, dan latar belakang pendidikan merupakan contoh sebagian data yang biasa disimpan oleh bagian sumber daya manusia. Informasi tentang faktor-faktor yang melandasi kerja karyawan sangat dibutuhkan perusahaan atau instansi, tidak hanya untuk menghindari kesalahan membuat keputusan yang tidak efektif, namun juga sebagai sarana mendayagunakan karyawan, sehingga mampu meningkatkan produktivitas kerja karyawan.

Begitu juga hal nya dengan adanya penerapan sistem informasi kepegawaian pada bidang sumber daya manusia. Sistem informasi yang dibangun mampu mengelola data personalia dengan fitur manipulasinya dan pencatatan yang terstruktur. Sistem juga dilengkapi fitur pencarian disetiap pencatatan data sehingga semakin memudahkan pengguna untuk mengubah atau menghapus data, tidak perlu dilakukan dengan cara melihat satu per satu data, akan tetapi tinggal dilakukan dengan menuliskan kata kunci. Sistem juga memberikan fitur informasi bagi pegawai cuti, pegawai yang akan memasuki masa habis kontrak maupun pensiun. Misalkan pada hasil seleksi yang dihasilkan sistem 
dan penilaian yang dilakukan secara kualitatif meminimalkan adanya penilaian secara subyektif, sehingga kandidat yang dihasilkan dapat menjadi bahan pertimbangan dalam pengambilan keputusan oleh manajer. Selain itu informasi yang diberikan mengenai pegawai dapat membantu manajer dalam pengambilan keputusan, misalkan saja membuka lowongan untuk mencari pengganti posisi karyawan yang akan memasuki masa habis kontrak maupun masa pensiun. Tak hanya itu, penerapan sistem informasi kepegawaian masih memiliki beberapa manfaat bagi karyawan sumber daya manusia di Rumah sakit Muhammadiyah Bandung yaitu dalam proses Pelacakan informasi data seorang pegawai akan lebih mudah dan cepat. Begitu juga dengan Pembuatan laporan yang bersifat rutin dan berkala akan mudah dikerjakan. Dapat mengetahui gambaran tentang nama-nama pegawai yang akan pensiun di masa mendatang dan nama pegawai yang akan naik pangkat berikut juga mengetahui daftar kenaikan gaji berkala di masa mendatang.

\section{SIMPULAN}

Berdasarkan pada hasil uji analisis regresi linier sederhana, Koefisien regresi pada variabel $\mathrm{X}$ memperoleh sebesar 0,769 . Koefisien regresi tersebut bernilai positif, tanda positif menunjukkan bahwa sistem informasi Kepegawaian memiliki pengaruh positif terhadap efektivitas kerja pada karyawan bidang sumber daya manusia di RS Muhammadiyah Bandung, dimana setiap kenaikan implementasi sistem informasi Kepegawaian sebesar 1 poin maka akan terjadi peningkatan efektivitas kerja sebesar 0,769 dan signifikan. Berdasarkan hasil uji koefisien determinasi, R square memperoleh sebesar 0,723 yang berarti bahwa Pengaruh Sistem Informasi Kepegawaian terhadap Efektivitas kerja memperoleh sebesar 72,3\% sisanya sebesar $27,7 \%$ di pengaruhi oleh variabel lain.

\section{UCAPAN TERIMA KASIH}

Pada kesempatan ini saya mengucapkan terimakasih kepada 1) Pihak Rumah Sakit yang telah memberikan izin peneliti dalam melakukan penelitian di Rumah Sakit Muhammadiyah Bandung serta semua responden yang bersedia terlibat dalam penelitian ini, 2) Politeknik Piksi Ganesha yang telah memberikan bantuan dan dukungan dalam menyelesaikan penelitian ini. 


\section{DAFTAR PUSTAKA}

Arisuniarti, D. M. (2016). Pengaruh Teknologi Informasi dan Sistem Informasi Manajemen Terpadu Terhadap Kinerja Karyawan di Lingkungan Universitas Warmadewa. Jurnal Administrasi Publik, 1(1).

Beti, I. Y. (2019). Sistem Pendukung Keputusan Pemilihan Karyawan Terbaik Menggunakan Simple Additive Weighting. ILKOM Jurnal Ilmiah, 11(28), 252-259. https://doi.org/https://doi.org/10.33096/ilkom.v11i3.480.252-259

Djahir, Y., \& Pratita, D. (2014). Bahan Ajar Sistem Informasi Manajemen (1st ed.). Deepublish.

Erliana, Akos, M., \& Priono, S. (2019). Pengaruh Disiplin Kerja Terhadap Kinerja Dengan Kepuasan Kerja Sebagai Variabel Intervening (Studi Pada Kantor Kecamatan Tatah Makmur Kabupaten Banjar). Jurnal Ilmu Administrasi Dan Manajemen, $\quad 3(2), \quad$ 1-28. http://ejournal.stiabinabanuabjm.ac.id/index.php/administraus

Hayatunnisa, N. U., Soepangat, S., \& Windiyaningsih, C. (2020). Analisis Penerapan Sistem Informasi Manajemen Rumah Sakit Di Unit Perawatan Intensif Rumah Sakit Kepresidenan RSPAD Gatot Soebroto Jakarta Tahun 2018. Jurnal Manajemen Dan Administrasi Rumah Sakit, 4(1).

Heldiansyah, Amellya, N., \& Assegaf, S. S. (2016). Sistem Informasi Kepegawaian Pada MTsN Mulawarman Banjarmasin Berbasis Web. Jurnal Sistem Dan Teknologi Informasi (POSITIF), 2(1), 28-33.

Hidayat, F. (2019). Konsep Dasar Sistem Informasi Kesehatan. Deepublish.

Ismail, F. F., \& Sudarmadi, D. (2019). Pengaruh Sistem Informasi Akuntansi Dan Sistem Pengendalian Internal Terhadap Kinerja Karyawan PT. Beton Elemen Persada. JASa ( Jurnal Akuntansi, Audit Dan Sistem Informasi Akuntansi ), 3(2), 40-53. https://doi.org/10.37151/jsma.v11i2.5

Lipursari, A. (2013). Peran Sistem Informasi Manajemen (Sim) Dalam Pengambilan $\begin{array}{llll}\text { Keputusan. JURNAL STIE } & \text { SEMARANG, }\end{array}$ http://jurnal3.stiesemarang.ac.id/index.php/jurnal/article/view/154/125

Mailani, R., \& Muhadi. (2016). Analisis Pengaruh Kepuasan Kerja Terhadap Kinerja Karyawan Bagian Manajemen Di Rsud Bhakti Dharma Husada Surabaya. Manajemen Kesehatan Yayasan RS.Dr.Soetomo, 2(2), 183-194.

Menteri Dalam Negeri No.17. (2000). Keputusan Menteri Dalam Negeri No:17 Tahun 2000 Tentang Sistem Informasi Manajemen Kepegawaian Departemen Dalam Negeri dan Pemerintah Daerah.

Mulyono. (2019). Analisis Regresi Sederhana. BINUS UNIVERSITY. https://bbs.binus.ac.id/management/2019/12/analisis-regresi-sederhana/

Rohani, K., \& Hati, S. W. (2018). Mengukur Kesuksesan Penggunaan Sistem Informasi Enterprise Resources Planning (Erp) Terhadap Kepuasan Pengguna dan Dampaknya. 2(2), 191-205.

Setiyadi, N. A., \& Hakam, F. (2015). Analisis Pelaksanaan Sistem Informasi Kesehatan di Klinik Muhammadiyah Medical Center (MMC) Universitas Muhammadiyah Surakarta. Jurnal IKESMA, $11(\mathrm{Mmc})$.

Sudiarti, T., Soepangat, S., \& Wiyono, T. (2019). Analisis Implementasi Sistem Informasi Manajemen di Instalasi Rawat Jalan Klinik Paru. Manajemen Kesehatan Yayasan RS.Dr.Soetomo, 5(1), 57-67.

Suharyanto, C. E., Chandra, J. E., \& Gunawan, F. E. (2017). Perancangan Sistem Informasi Penggajian Terintegrasi Berbasis Web ( Studi Kasus di Rumah Sakit St . Elisabeth ). Jurnal Nasional Teknologi Dan Sistem Informasi, 3, 225-232.

Suryana, N. A. (2018). Kinerja Sistem Informasi Manajemen Kepegawaian (Simpeg) Dalam Mendukung Pelayanan Kepegawaian di Pusat Humaniora, Kebijakan Kesehatan dan Permberdayaan Masyarakat Surabaya. Jurnal UNESA. 
Lusi Liani Lestari, Ai Susi Susanti : Pengaruh Sistem Informasi Kepegawaian Terhadap ....

Waruwu, S. (2018). Analisis Pengaruh Lingkungan Kerja, Kompensasi Dan Kepemimpinan Terhadap Efektivitas Kerja Karyawan. JENIUS (Jurnal Ilmiah Manajemen Sumber Daya Manusia), 1(3), 281-289. https://doi.org/10.32493/jjsdm.v1i3.1290

\begin{tabular}{|l|l|}
\hline Submission & $05-07-2021$ \\
\hline Review & $01-08-2021$ \\
\hline Accepted & $23-09-2021$ \\
\hline Publish & $29-10-2021$ \\
\hline DOI & $10.29241 /$ jmk.v7i2.643 \\
\hline Sinta Level & 3 (Tiga) \\
\hline
\end{tabular}

